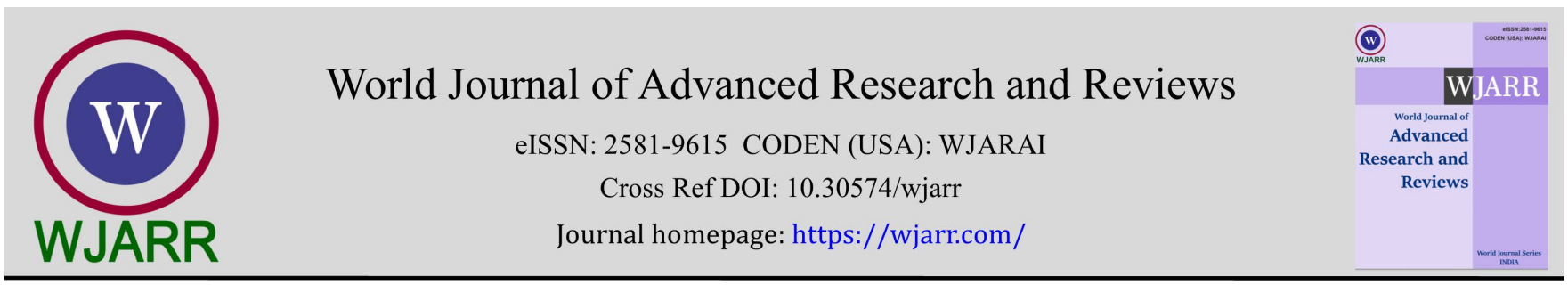

(RESEARCH ARTiClE)

\title{
Quality hypertension care: Barriers and drivers for implementation among primary health care staff
}

\author{
Saratu Omagbemi Ajike * and Mfonobong Ubong Obot \\ Department of Public Health, School of Public \& Allied Health, Babcock University, Ilisan-Remo, Ogun State, Nigeria
}

World Journal of Advanced Research and Reviews, 2021, 09(02), 018-026

Publication history: Received on 20 January 2021; revised on 29 January 2021; accepted on 01 February 2021

Article DOI: https://doi.org/10.30574/wjarr.2021.9.2.0036

\begin{abstract}
Offering quality hypertension care remains a challenge in many Sub-Saharan regions including Nigeria where rates of hypertension continue to increase. Understanding factors affecting care can provide mechanisms for service improvement to promote better quality of care for hypertensives. Exploratory study using qualitative method of data collection was conducted among 17 clinical service staff in 15 Primary Health Care centres with at least 5 years of experience. Participants were selected through purposive and convenience sampling. Data collected was coded and analysed using thematic analysis and SPSS version 22 to compute frequency distribution of sociodemographic characteristics. Most (64.7\%) were female and $41.2 \%$ had up to 10 years of working experience and were Nurses (49\%). This study revealed that participants are still faced with barriers that hinder them from delivering quality healthcare services which affects the implementation of quality hypertension care required in the primary health centre. However, participants identified strategies that can be used to address the barriers towards implementation of quality hypertension care. Despite the worrying prevalence of cases, offering quality hypertension care remains a challenge. There is need for increased attention at the grassroots for improved resources to aid positive service output.
\end{abstract}

Keywords: Hypertension; Nigeria; Primary Health Care; Quality Care

\section{Introduction}

Hypertension remains of public health importance globally. It contributes significantly to premature death and has also been identified as a major cause of disability-adjusted-life years [1]. Globally, hypertension is the leading cause of cardiovascular disease and cardiovascular death responsible for 55\% of the 17 million deaths annually [2] and a projected increase of up to 1.56 million cases by 2025 [3]. Globally, Africa contributes the largest burden of hypertension and is worsened by low rates of awareness, treatment and control. [4] According to a recent WHO report [5], it is estimated that the African continent has the highest prevalence rate of hypertension of $46 \%$ among adults aged 25 years and above compared to the Americas (18\%) [6], East Mediterranean (26\%) [7], South East Asia (27\%) [8] and Western Pacific (5-48\%) [9]. Consequently, the World Health Organization (WHO) is targeting a 25 per cent global reduction in uncontrolled hypertension by 2025[10].

Nigeria, with a population of over 190 million [11] is the most populous nation in Africa and may be contributing substantially to the burden of hypertension in Africa. About $48 \%$ of this large population reside in cities while the remaining 52\% reside in rural areas. In Nigeria, the estimated overall hypertension prevalence is $28.9 \%$ [12] as compared with other countries such as Burkina Faso (18\%) [13] and Ghana (22\%) [14]. Within the country, rates in the last seven years have varied between and within regions. Studies, [15][16] in the south-west region have reported rates of between $9 \%$ and $50 \%$, in the south-east between $22 \%$ and $35 \%$ [17][18][19], the North, [20][21][22] between 25\%

\footnotetext{
* Corresponding author: Saratu Omagbemi Ajike

Department of Public Health, School of Public \& Allied Health, Babcock University, Ilisan-Remo, Ogun State, Nigeria. 
and 33\% and in the South-South region, [23][24][25] between 21\% and 44\%. A study by Akpan et al had been carried out in this study's setting of Akwa-Ibom and reported a much higher rate of $44.3 \%$, thereby suggesting a high prevalence needing attention.

Provided with evidence of a definite increase in the number of cases of hypertension in Nigeria, appropriate interventions need to be developed and implemented to reduce the preventable burden of hypertension especially at Primary Health Care (PHC) centres which are the first contact for over 55\% of the Nigerian population [26] and the only source of formal care in many regions of Nigeria [27].

The International Forum for Hypertension Control and prevention in Africa had provided over a decade ago sciencebased and cost- effective guidelines for the prevention, diagnosis and management of hypertension in Sub-Saharan Africa [28]. Despite the availability of a standard benchmark, poor levels of awareness, treatment, blood pressure control and a high burden of hypertension related complications still abound [29] contributing to poor quality of care and poor outcomes such as poor achievement of recommended blood pressure levels especially in rural settings [30].

The quality of health care for hypertensive patients is the degree to which hypertensive health services for hypertensive patients increase the likelihood of timely, appropriate care for the purpose of achieving desired outcomes that are both consistent with current professional knowledge and take into account the preferences and aspirations of individual hypertensive patients [31].

Increasing awareness by policy makers towards Non-communicable Disease including hypertension has led to the establishment of infrastructures geared towards prevention and control [32]. However, these are often not efficacious due to underfunding, non-operational frameworks and a dearth of environmental perspectives. Since providing good quality care is essential to appropriate care, an understanding of the factors which affect this care is imperative. Thus, this study sought to obtain perspectives from health care providers in PHC centres to understand the factors related to the provision of quality hypertension care in Akwa-Ibom, South-East, Nigeria. The information obtained can serve as a resource for the state's leadership in the control and management of hypertension in PHC facilities.

\section{Material and methods}

\subsection{Study Design and population}

This study employed a qualitative design to understand factors affecting the provision of quality hypertension care in a South-South region of Nigeria from August 2019 to February 2020.

\subsection{Study Sample and Technique}

The study participants comprised staff in PHC centres in the Local Government Areas within Akwa-Ibom State. These staff included nurses, pharmacists, laboratory scientists, clinical officers, community health extension workers and excluded non-clinical support staff. Staff who had up to five years of experience were purposively selected. These centres were randomly selected from the local government areas in the 3 senatorial districts in Akwa-Ibom State. Respondents were recruited through a multi stage sampling procedure. First, a sampling frame consisting of the 3 senatorial districts and corresponding local government areas was obtained. Secondly, 5 LGAs were randomly selected from each of the senatorial districts. The apex PHC centre was accessed in each of the LGAs and permission to interview only two staff was given by the Director during the working hours. These staff were those who were identified by the centre Director and gave consent. During data collection, data saturation as described by Saunders et al [33] was reached by the 17 th staff. The study was approved by the Health Research Ethics Committee of the authors' institution.

\subsection{Data collection method}

Structured in-depth interviews were used to obtain information concerning the factors affecting quality hypertension care. Each interview was held following a full description of the study and consent to continue with the interview from the participants. Interviews lasted for an average of 30 minutes.

\subsection{Data analysis}

The data obtained from the interview was transcribed verbatim and analysed thematically. Following transcription, the responses were read and reread and similar themes across all responses were then noted. Themes were then placed within the identified themes and summarized. 


\section{Results}

\subsection{Participants' characteristics}

Of the 17 PHC staff interviewed, 11(64.7\%) of these participants were female (23.5\%) and nurses (49\%) which included junior and senior nursing officers, public health nursing officer, mid-wives and 7 (41.2\%) of the participants had up to 10 years working experience in the primary health care facility (Table 1 ).

Table 1 Demographic characteristics of participants

\begin{tabular}{|l|l|}
\hline \multirow{2}{*}{ Variables } & Participants in the study N-17 \\
\cline { 2 - 2 } \multicolumn{2}{|l|}{ Frequency N (\%) } \\
\hline Gender & $\begin{array}{l}\text { F(35.3) } \\
\text { Female }\end{array}$ \\
\hline Age & $11(64.7)$ \\
\hline 31 -35 & $4(23.5)$ \\
36 \& above & $13(76.5)$ \\
\hline Religion & $17(100)$ \\
\hline Christian & $17(100)$ \\
\hline Ethnicity & $1(5.9)$ \\
\hline Efik/lbibio & $1(5.9)$ \\
\hline Years of working experience & $1(5.9)$ \\
\hline 2 & $2(11.8)$ \\
4 & $3(17.6)$ \\
5 & $1(5.9)$ \\
7 & $7(41.2)$ \\
8 & $1(5.9)$ \\
\hline 9 & $1(5.9)$ \\
10 & $1(5.9)$ \\
11 & $4(23.5)$ \\
\hline Work position & $3(17.6)$ \\
\hline Director & $1(5.9)$ \\
Nurse superintendent & $1(5.9)$ \\
Nurse & $3(17.6)$ \\
Nurse/Midwife & $3(17.6)$ \\
Public health nursing officer & \\
Pharmacist & \\
Head of facility & \\
\hline
\end{tabular}

\subsection{Quality of hypertension care in the health centre}

The respondents recognised the need to provide quality hypertension care which was understood to be and within the scope of PHCs including, appropriate referral by recognising cases requiring higher level of care. This was highlighted by the respondents who said, 
"The care does not have much to do with treating higher cases. Although we treat hypertension, but mainly what we handle here are minor cases then we refer very severe cases to secondary healthcare and the teaching hospital is the tertiary healthcare. All the same it doesn't mean that we don't handle hypertensive cases, we do handle hypertensive cases". [D-NA]

"Meanwhile this is a Primary Health Care Centre and in PHC you know we give limited care you know that is we don't...there are some cases we don't handle. If a client's condition will need a higher care, we will have to refer except it is a mild case of hypertension. If it is a mild hypertension then we can go ahead with the clients". [CPHN-NU]

\subsection{Favourable factors in the implementation of quality hypertension care}

Currently, those factors promoting quality hypertension care are the availability of drugs at subsidized rates and other essential resources, trained workforce who experienced, good record are keeping system, regular training opportunities and an active response system of suspected cases. In addition, the presence of knowledgeable staff was a sub-theme that emerged. As highlighted, the following comments suggested the aforementioned.

"The government supply drugs to the Primary Health Care Centre for hypertensive clients so they are given at subsidized rates". [P-NA]

"Every staff in this Primary Health Care Centre are professionals that have been trained to handle cases of hypertension". [D-NA]. Another respondent added, “.... the staff in the Primary Health Care Centre have knowledge on hypertension and have also gained experience over the years in their respective fields". [D-NA]

"We have a record keeping system used to keep record of clients so that it is easy to do a follow up and continue treatment. The clients buy a card and their details are written inside and they are asked to bring it to the Primary Health Care Centre every time they visit". [NM-AB]

"Members of the community come to the Primary Health Care Centre when they notice any symptoms. They complain and go ahead to get tested". [P-NA]

"We do carry out awareness and sensitization campaigns which enables us to inform the members of the public about hypertension". [CPHN-NU]

"From time to time there are training workshops organized for staff of the Primary Health Care Centre to increase knowledge and introduce new guideline and pattern of healthcare delivery. The training is usually done for the Heads of units and then stepped down to the other staff". [NM-AB]

\subsection{Factors limiting the implementation of quality hypertension care}

The major barriers mentioned were in terms of cultural barriers, systemic and patients' sickness response and other socioeconomic factors. Respondents highlighted these and said,

"A major barrier is superstition. Some people believe that hypertension is connected to superstition so they believe God will heal them or fall back on herbs". [D-OK]

“Another barrier is that clients don't adhere to medication. When this happens, the hypertensive condition worsens and moves from mild to severe which cannot be handled in the Primary Health Care Centre. In such cases we refer them for advanced care". [NM-IK]

"Poverty is another factor. We notice that some of the clients are not able to afford the antihypertensive drugs and sometimes even when they are subsidized some may not still afford them". [P-NA]

"Sometimes the drugs supplied by the government do not come on time. So, when we run out of drugs, we simply collect money from the clients and go to a different facility to get the drugs for them. When we exhaust drugs from the other facility, we usually have nothing to give so we refer them to places where they can purchase it by themselves". [N-IN]

“In this Primary Health Care Centre, we are short staffed and what we do is we run on shifts. Because we don't have adequate number of staff, we are not able to attend to clients on time which can also alter blood pressure reading. If the client waits too long and begins to complain or shout, when it is time to check the blood pressure it is impossible to get the correct diagnosis which can lead to giving wrong treatment". [N-OR] 
"Because of poverty, lack of knowledge or superstition some clients patronize quacks. The activity of quacks has made it difficult for them to seek care in the Primary Health Care Centre thereby worsening the case". [P-NA]

"Some of the blood pressure apparatus supplied by the government do not last and because they have been in the facility for years become faulty and this can cause wrong reading of blood pressure of clients". [CPHN-NU]

"In the aspect of staff, for some time they were not recruiting and people were also retiring especially the nurses and the available staff during their shifts who are not trained to handle hypertension cases would not know what to do". [PIB]

'The clients have a poor health seeking behaviour. They are not willing to visit the Primary Health Care Centre and are not willing to seek for help". [N-IA]

"The Primary Health Care Centre is not emphasized as the first point of care for the client. And I think this is one of the reasons why some of them go for traditional medicine". [NS-IT]

\subsection{Strategies to address the barriers for implementing quality hypertension care}

To address the barriers goals must be set, action must be taken to achieve the goals and resources must be mobilized to execute those actions. One of the major strategies that was mentioned was prompt supply and collaborative provision of drugs including provision of impress, and sensitization of the public. Other strategies mentioned were equipping the health care facility, employment of qualified professionals and presence of doctors in the system, emphasis on primary health care centres and regular training of staff. Participants responses were,

“Usually we used to have drugs supplied by sponsors and not just the government. I don't know why they stopped but I think that they should be brought back into the system of drug procurement. That will enable the drugs to be less expensive for the clients". [D-NA]. Another added that, "There is need for continuous drug supply. The government used to provide impress, that is money given for upkeep, to every Primary Health Care facility and this money is usually used to procure equipment and resources for the facility when the others have been exhausted". [D-OK]

"I think one of the strategies should be client education, sensitization and awareness. They should be informed on the dangers of not adhering to their medication and diet. They should be encouraged to carry out routine check-ups and seek medical attention when needed"... "Emphasis should be made on the Primary Health Care Centre and people should be encouraged to access the health centre for care". [N-IA]

"Equipping the health facility will also help improve the quality of service rendered. If you look around you will notice faulty equipment and old ones that have not been changed". [NM-EK]

"Before we used to have doctors working in the Primary Health Care Centre and it used to be easier for us, it made our work easy and also easy for the client but now the doctors have been taken away. I think it will be a good idea for the government to bring back doctors to the system. Not just doctors who are looking to make profit but those who are in the business of saving lives". [CPHN-NU]

"The government should employ qualified staff, especially professional health staff. During the period when the nurses were retiring, they employed food scientist and other staff who were not really needed in the Primary Health Care Centre at that time. So, these people didn't know how to use the blood pressure apparatus and check blood pressure and that was a burden for us because most of the staff had to work two shifts just to handle such cases". [NM-IE]

\section{Discussion}

Interviews with the PHC staff raised important issues that point to strengths and weaknesses that are encountered within the health system. Okpetu et al [34] had linked low quality care to weak information system, referral linkages between primary care and secondary/tertiary care facilities, deficiency in knowledge, poor resourcing and inadequate human resources. The respondents highlighted a number of these as barriers to their provision of quality hypertension care. A very important point raised was that despite personal efforts, quality of hypertension care in the Primary Health Care system is low and the ability of primary care staff to offer quality hypertension care is limited by certain barriers. PHC centres remain the acclaimed first point of care. However, findings in this study suggest deficits in motivating these centres' capacities to operate as first responders, especially in hypertension care. Indeed, if PHC centres are the first point of care healthcare seeking, the essential elements must be put in place and monitored for sustainability and better 
health outcomes. Furthermore, the statements are suggestive of poor continuity of and fragmented government support.

The participants shared the enablers that facilitate the implementation of quality hypertension care in the health centre which includes the supply of drugs by the government to the Primary Health Centre for the hypertensive patients. Others reported differently. In other studies [35][36] the supply of essential drugs was a barrier to hypertension treatment and management. This study suggests differently the positive efforts being put in place to ensure availability of essential drugs.

The study participants expressed that the barriers cut across the government and patients. As Kayima et al [37] opined, barriers can generally be categorized as health system deficiencies, patients' non-adherence and the physicians' inertia in treating hypertension, the lack of anti-hypertensive medication at health facilities and the long distance to the health facilities. Hence, the barriers are similar to other findings in a typical health facility and continue to plague systems of care.

Participants identified strategies which they felt could ameliorate the current deficits in the system and strengthen the provision of a better quality of care. They expressed the need for the inclusion of doctors in service delivery. While this seems laudable, it left a question as to why doctors in particular, since studies [38][39] demonstrated effectiveness of other health professionals in managing hypertension. Others [40] further opined that due to increasing workload there may be need for new models, implying the need for other professionals. These point to the possibility of engaging with other trained health professionals which was not considered in this study. However, their views might have been based on previous norm.

Sensitization campaign was also highlighted as a mechanism for improving care Sensitization can be used to create awareness and inform the public on the symptoms, causes, treatment and control of hypertension. As recommended by Beune et al [41], patient education and staff education can improve knowledge on hypertension and communicate new trends on hypertension to staff. Moreover, beyond mere education, Saha [42] recommended patient-centred education involving understanding of beliefs and needs to improve treatment.

\subsection{Strengths and Limitations}

Strengths of this study include interviewing experienced participants as guided by standards of qualitative research to gather rich data saturation which in this study aided in-depth study into the factors affecting the provision of quality hypertension care in primary health care. On the other hand, the design of the study limits the generalizability of the study to other areas.

\section{Conclusion}

PHC staff are still faced with barriers that hinder delivering the best quality hypertension care. Despite the existence of best practice standards. There is a need for more active support from the government and other concerned parastatals to facilitate the best possible care for hypertensive patients including a revisit of workable frameworks.

\section{Compliance with ethical standards}

\section{Acknowledgments}

Th authors would like to thank the PHC staff who participated in the study.

\section{Disclosure of conflict of interest}

The authors declare no conflict of interest.

\section{Statement of informed consent}

Informed consent was obtained from all individual participants included in the study. 


\section{References}

[1] GBD 2017 Risk Factor Collaborators, “Global, regional, and national comparative risk assessment of 84 behavioural, environmental and occupational, and metabolic risks or clusters of risks for 195 countries and territories, 1990-2017: a systematic analysis for the Global Burden of Disease Study 2017. Lancet. 2018; 392:1923-1994.

[2] World Heart Federation, "Elevating Hypertension on the Public Health Agenda. [Internet]. Geneva: World Heart Federation; (C) 2017 [May, 17, 2017; cited 2020 November 11]. Available from https://www.world-heartfederation.org/news/elevating-hypertension-public-health-agenda/

[3] Tabrizi JS, Sadeghi-Bazargani H, Farahbakhsh M, Nikniaz L, Nikniaz Z. Prevalence and Associated Factors of Prehypertension and Hypertension in Iranian Population: The Lifestyle Promotion Project (LPP). PLoS One. 2016; 11(10):e0165264.

[4] Adeloye D, Basquill C, Aderemi AV, Thompson JY, Obi FA. An estimate of the prevalence of hypertension in Nigeria: a systematic review and meta-analysis," Journal of Hypertension. 2015; 33(2):230-242.

[5] World Health Organisation: Hypertension Global Health Observatory data. [Internet]. Geneva: World Health

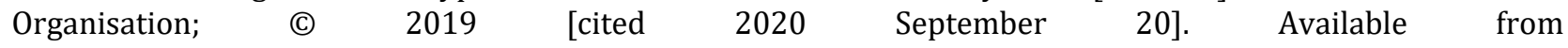
https://www.who.int/gho/ncd/risk_factors/blood_pressure_prevalence_text/en/

[6] World Health Organisation. Hypertension. [Internet]. Geneva: World Health Organisation; (C) 2019 [cited 2020 September 20]. Available from https://www.who.int/news-room/fact-sheets/detail/hypertension.

[7] Musaiger AO, Al-Hazzaa AM. Prevalence and risk factors associated with nutrition-related noncommunicable diseases in the Eastern Mediterranean region. International Journal of General Medicine. 2012; 5:199-217.

[8] Neupane D, McLachlan CS, Sharma R, Gyawali B, Khanal V, Mishra SR, Christensen B, Kallestrup P. Prevalence of hypertension in member countries of South Asian Association for Regional Cooperation (SAARC): systematic review and meta-analysis. Medicine. 2014; 93:e74.

[9] Martiniuk AL, Lee CM, Lawes CM, Ueshima H, Suh I, Lam TH. Et al. Hypertension: its prevalence and population-attributable fraction for mortality from cardiovascular disease in the Asia-Pacific region. Journal of Hypertension. 2007; 25:73-79.

[10] World Health Organisation. Global NCD target: Reduce high blood pressure [Internet]. Geneva: World Health Organization; (C) 2016 [ 2020 September 23]. Available from https://www.who.int/beat-ncds/takeaction/policy-brief-reduce-high-blood-pressure.pdf

[11] The World Bank. Population, total, Nigeria. [Internet]. Washington DC: The World Bank Group; C 2020 [September 2020 13]. Available from https://data.worldbank.org/indicator/SP.POP.TOTL?locations=NG

[12] Okubadejo NU, Ozoh OB, Ojo 00, Akinkugbe AO, Odeniyi IA, Bello BT, Agabi OP. Prevalence of hypertension and blood pressure profile amongst urban-dwelling adults in Nigeria: a comparative analysis based on recent guideline recommendations, Clinical Hypertension. 2019; 25:1-9.

[13] Soubeiga JK, Millogo T, Bicaba BW, Doulougou B, Kouanda S. Prevalence and factors associated with hypertension in Burkina Faso: a countrywide cross-sectional study," BMC Public Health. 2017; 17(64):64.

[14] Sanuade OA, Boatemaa S, Kushitor MK. Hypertension prevalence, awareness, treatment and control in Ghanaian population: Evidence from the Ghana demographic and health survey. PLoS One. 2018; 13:e0205985

[15] Ajayi IO, Sowemimo IO, Akpa OM, Ossai NE. Prevalence of hypertension and associated factors among residents of Ibadan-North Local Government Area of Nigeria. Nigerian Journal of Cardiology. 2016; 13:67-75.

[16] Ajayi IO, Soyannwo MAO, Asinobi AO, Afolabi NB, Ayede IA, Bamgboye EA. Blood pressure pattern and hypertension related risk factors in an urban community in Southwest Nigeria: The Mokola hypertension initiative project, Ibadan, Nigeria," Journal of Public Health \& Epidemiology. 2017; 9:51-64.

[17] Ogah OS, Madukwe 00, Chukwuonye II, Onyeonoro UU, Ukegbu AU, Akhimien MO, Onwubere BJ, Okpechi IG. Prevalence and determinants of hypertension in Abia State Nigeria: results from the Abia State NonCommunicable Diseases and Cardiovascular Risk Factors Survey. Ethnicity \& Disease. 2013; 23(2):161-167.

[18] Ugwuja E, Ezenkwa U, Nwibo A, Ogbanshi M, Idoko O, Nnabu R. Prevalence and determinants of hypertension in an agrarian rural community in southeast Nigeria. Annals of Medical and Health Sciences Research. 2015; 5(1): 45-49. 
[19] Ezekwesili CN, Ononamadu CJ, Onyeukwu OF, Mefoh NC. Epidemiological survey of hypertension in Anambra state, Nigeria. Nigerian Journal of Clinical Practice. 2016; 19(5):659-6.

[20] Gezawa ID, Musa BM, Mijinyawa M, Talle MA, Shehu YM, Uloko AE, Watila MM, Musa BM. Prevalence of hypertension and its relationship with indices of obesity in Maiduguri, Northeastern Nigeria. Nigerian Journal of Basic and Clinical Sciences. 2014; 11(2):67-71.

[21] Karaye KM, Yakasai MM, Abdullahi U, Hamza M, Dalhat MM, Gwaram BA, Habib ZG, Bello MM, Yakasai AM, Sadauki AH, Sarkin-Fada F, Abubakar UB, Habib AG. Hypertension and other cardiovascular risk factors in a semi-nomadic Fulani population in Kano, Nigeria. Nigerian Journal of Cardiology. 2015; 12(2):124-8.

[22] Vincent-Onabajo GO, Adaji J0, Umeonwuka CI. Prevalence of Undiagnosed Hypertension Among Traders at A Regional Market in Nigeria. Annals of Medical Health Science Research. 2017; 7:97-101.

[23] Akpan EE, Ekrikpo UE, Udo AIA, Bassey BE. Prevalence of Hypertension in Akwa- Ibom State South-South Nigeria: Rural versus Urban Communities Study. International Journal of Hypertension. 2015;(975819):5 pages.

[24] Egbi OG, Rotifa S, Jumbo J. Prevalence of hypertension and its correlates among employees of a tertiary hospital in Yenagoa, Nigeria. Annals of African Medicine. 2015; 14(1):8-17.

[25] Alikor CA, Emem-Chioma PC, Odia OJ. Hypertension in a Rural Community in Rivers State, Niger Delta Region of Nigeria: Prevalence and Risk Factors. The Nigerian Health Journal. 2013; 13(1):18-25.

[26] Akinlua JT, Meakin R, Umar AM, Freemantle N. Current Prevalence Pattern of Hypertension in Nigeria: A Systematic Review. PLoS One. 2015; 10(10):e0140021,

[27] Akinlua JT, Meakin R, Bashir I, Freemantle N. Beliefs about hypertension among primary health care workers and clients in Nigeria: A qualitative study. PLoS one. 2018; 13(12):e0209334.

[28] Lemogoum D, Seedat YK, Mabadeje AF, Mendis S, Bovet P, Onwubere B, Blackett KN, Lenfant C, Kabangu JR, Block $\mathrm{P}$, Belhocine $\mathrm{M}$, Degaute JP. International Forum for Hypertension control and prevention in Africa. Recommendations for prevention, diagnosis and management of hypertension and cardiovascular risk factors in sub-Saharan Africa. Journal of Hypertension. 2003; 21(11):1993-2000.

[29] Ataklte F, Erqou S, Kaptoge S, Taye B, Echouffo-Tcheugui JB, Kengne AP. Burden of undiagnosed hypertension in sub-saharan Africa: a systematic review and meta-analysis," Hypertension. 2015; 65(2):291-8.

[30] Gibson O, Lisy K, Davy C, Aromataris E, Kite E, Lockwood C, Ritano D, McBride K, Brown A. Enablers and barriers to the implementation of primary health care interventions for Indigenous people with chronic diseases: a systematic review. Implementation Science. 2015; 10:71.

[31] Rasha K, Schwalm J, Yusuf S, Brian H, Martin M, Maheer K, Robby N. Patient and Healthcare Provider Barriers to Hypertension Awareness, Treatment and Follow Up: A Systematic Review and Meta-Analysis of Qualitative and Quantitative Studies. PLOS One. 2014; 9(1):1-12

[32] Lee DE, Cooper RS. Recommendations for global hypertension monitoring and prevention," Current Hypertension Reports. 2009; 11: 444-449.

[33] Saunders B, Sim J, Kingstone T, Baker S, Waterfield J, Bartlam B, Burroughs H, Jinks C. Saturation in qualitative research: exploring its conceptualization and operationalization. Quality \& Quantity. 2018; 52:1893-1907.

[34] Okpetu EI, Abimbola S, Koot JAR, Kane S. Implementing Prevention Interventions for Non-Communicable Diseases within the Primary Health Care System in the Federal Capital Territory, Nigeria. Journal of community Medicine \& Primary Health Care. 2018; 30:1-18.

[35] Peck RN, Shedafa R, Kalluvya S, Downs JA, Todd J, Suthanthiran M, Fitzgerald DW, Kataraihya JB. Hypertension, kidney disease, HIV and antiretroviral therapy among Tanzanian adults: a cross-sectional study. BMC Medicine. $2014 ; 12: 125$.

[36] Thorogood M, Connor M, Tollman S, Lewando Hundt G, Fowkes G, Marsh JA. Cross-sectional study of vascular risk factors in a rural South African population: data from the Southern African Stroke Prevention Initiative (SASPI). BMC Public Health. 2007; 7:326.

[37] Kayima J, Wanyenze RK, Katamba A, Leontsini A, Nuwaha F. Hypertension awareness, treatment and control in Africa: a systematic review. BMC Cardiovascular Disorder. 2013; 13(54). 
[38] Ndou T, van Zyl G, Hlahane S, Goudge J. A rapid assessment of a community health worker pilot programme to improve the management of hypertension and diabetes in Emfuleni sub-district of Gauteng Province, South Africa. Global Health Action. 2013; 6:19228.

[39] Albasri A, Clark CE, Omboni S, McDonagh STJ, McManus RJ, Sheppard JP. Effective detection and management of hypertension through community pharmacy in England. The Pharmaceutical Journal. 2020; 304.

[40] Hobbs F, Bankhead C, Mukhtar T, Stevens S, Perera-Salazar R, Holt T, Salisbury C. National Institute for Health Research School for Primary Care Research. Clinical workload in UK primary care: a retrospective analysis of 100 million consultations in England 2007-14. Lancet (London, England). 2016; 387:2323-2330.

[41] Beune EJ, Haafkens JA, Bindels PJ. Barriers and enablers in the implementation of a provider-based intervention to stimulate culturally appropriate hypertension education," Patient Education and Counseling. 2011; 82(1):7480 .

[42] Saha S. Patient Centeredness, Cultural Competence and Healthcare Quality. Journal of the National Medical Association. 2008; 100:1275-1284. 